\title{
QUANDO A SUSTENTABILIDADE (OU SEU DISCURSO) SE DESFAZ COM UMA CRISE: O CASO VALE
}

MARTA CARDOSO DE ANDRADE UNIVERSIDADE SALVADOR SALVADOR, BAHIA, BRASIL DRAMARTAANDRADE@GMAIL.COM 


\section{QUANDO A SUSTENTABILIDADE (OU SEU DISCURSO) SE DESFAZ COM UMA CRISE: O CASO VALE}

Resumo: Este trabalho visa estudar como a Sustentabilidade Empresarial (ou seu discurso) se desfaz diante de uma crise mal gerida. Para tanto, analisou-se a crise vivenciada pela Vale desencadeada a partir do rompimento da barragem dessa companhia em Córrego do Feijão, Brumadinho (MG). Para tanto, faz-se uma revisão teórica de conceitos de Sustentabilidade e de Discurso, bem como os de crise e gestão dessa, visando analisar o caso em questão, o qual foi acompanhado em cobertura jornalística, entre 25/01 e 24/02/19, via Jornal Hoje da Rede Globo de Televisão. Como resultado, obteve-se o posicionamento da Vale frente ao ocorrido terminou por desencadear uma crise de imagem.

Palavras-chave: Sustentabilidade Empresarial; Crise; Vale.

\section{CUANDO LA SOSTENIBILIDAD (O SU DISCURSO) SE ROMPE CON UNA CRISIS: EL CASO VALE}

Resumen: Este documento tiene como objetivo estudiar cómo la sostenibilidad corporativa (o su discurso) se desmorona ante una crisis mal gestionada. Con este fin, analizamos la crisis experimentada por Vale provocada por la ruptura de la presa de esta empresa en Córrego do Feijão, Brumadinho (MG). Por lo tanto, se realiza una revisión teórica de los conceptos de Sostenibilidad y Discurso, así como los de crisis y gestión, con el objetivo de analizar el caso en cuestión, que se siguió en la cobertura de noticias, entre el 25/01 hasta 24/24/19, vía Jornal Hoje (JH) de Rede Globo de Televisão. Como resultado, se logró la posición de Vale frente al evento, desencadenando una crisis de imagen.

Palabras clave: Sostenibilidad empresarial; Crisis; Vale.

\section{WHEN SUSTAINABILITY (OR ITS DISCOURSE) BREAKS DOWN WITH} A CRISIS: THE VALE CASE

Abstract: This paper aims to study how Corporate Sustainability (or its discourse) falls apart in the face of a poorly managed crisis. To this end, we analyzed the crisis experienced by Vale triggered by the rupture of the dam of this company in Córrego do Feijão, Brumadinho (MG). Therefore, a theoretical review of the concepts of Sustainability and Discourse, as well as those of crisis and management, is carried out, aiming to analyze the case in question, which was followed in news coverage, between 01/25 to 02/24/19, via Jornal Hoje of Rede Globo de Televisão. As a result, Vale's position in the face of what happened ended up triggering an image crisis.

Keywords: Business Sustainability; Crisis; Vale. 


\section{INTRODUÇÃO}

A preocupação generalizada com as questões sociais e ambientais conduziu as organizações a incorporarem a dimensão da sustentabilidade empresarial (SE) nos modelos de gestão dos seus negócios, principalmente como estratégia competitiva. Igualmente, os públicos têm pressionado as empresas a atenderem demandas focadas em melhor qualidade de vida para as pessoas e para a preservação do meio ambiente, considerando, dessa forma, o impacto das operações corporativas dentro e fora "dos seus murros".

Nesse sentido, as organizações querem vincular sua imagem e construir uma reputação sobre iniciativas que considerem a responsabilidade socioambiental e que adotem práticas que contribuam para o desenvolvimento sustentável (DS). A SE tornou-se, assim, um componente constante no cenário corporativo e a adoção dessas práticas sustentáveis atrai a atenção de novos públicos que se preocupam com o ecossistema e com questões sociais; da mesma forma que as empresas as quais não se preocupam com essas questões perdem imagem e capital reputacional e, em última instância, muito valor dependendo do resultado de suas ações naquele tocante. Entretanto, observa-se que não basta possuir práticas sustentáveis, faz-se necessário divulgá-las e convencer a opinião pública (OP) que as possui e das suas "boas" intensões para com o social e com o ambiental, destacando esforços e resultados. Assim, discurso e prática devem estar juntos na atuação das corporações.

Quando esses não "caminham" juntos, as organizações estarão, mais dia menos dia, em situação de crise instaurada e, consequentemente, com perda de credibilidade, imagem e reputação. Dessa maneira, este estudo faz uma breve revisão teórica do que vem a ser: a SE, o seu discurso e explicitação desse; o que constitui e é uma crise, outrossim, como a gerir, visando-se entender: a atuação da Vale, no tocante à SE, e como essa se posicionou frente ao rompimento da barragem do Córrego do Feijão em Brumadinho (MG), resultando numa das maiores crise atravessadas por essa companhia.

Para tanto, metodologicamente, acompanhou-se a cobertura jornalística dos principais acontecimentos desde o referido rompimento, entre 25/01 até 24/02/19, um mês após o acontecido, e os posicionamentos adotados pelos dirigentes da Vale. Isso foi feito via Jornal Hoje (JH) da Rede Globo de 
Televisão'. O motivo da escolha desse veículo, precipuamente, deu-se por ter sido um dos primeiros a noticiar o citado rompimento em 25/01/19, por volta das 13h25, uma vez que esse jornal estava no ar no momento em que ocorreu o fato em questão. Igualmente foi feita uma pesquisa bibliográfica para embasar este estudo, como também foi realizada uma pesquisa documental em relatórios acerca da SE praticada pela Vale, bem como no site dessa corporação.

\section{CENÁRIO E CONCEITOS IMPORTANTES}

Já existe, há mais ou menos 40 anos, alguma consciência de que a sociedade e o planeta vivenciam um momento de transição e que um teria de se conciliar com o outro para conseguirem continuar a existir. Naquela época, pensava-se numa emergente etapa mais abundante que a anterior no tocante da inovação e de um "capitalismo verde" - expressão cunhada, em 1987, por John Elkington (COMIN, 2016, p. 14), entretanto, não foi isso o presenciado. Nos anos de 1970, o futuro começou a ser percebido de forma mais pessimista e a sensação de degradação passou a ser sentida incisivamente e a sensação de "crise" instalou-se (MASI, 1999). Dessa forma, o método mais apropriado para contrapor o modelo civilizatório vigente, o qual se apresenta ineficaz frente aos novos desafios da atualidade, é a proposição de modelos alternativos.

Nesse cenário, sob a hodierna consciência e pressão de alguns grupos, nota-se uma alteração do que se espera acerca das responsabilidades inerentes às organizações e de como essas devem relacionar-se com ambiente natural, com a sociedade e com seus stakeholders. Ao seguir essa linha de conscientização, a partir da década de 1990, observa-se que as corporações começam a se comprometer com o desenvolvimento social e ambiental, aperfeiçoando suas ações para que tenham impactos positivos na sociedade. Assim, Instituto Ethos (2004 apud NAVES, 2009, p. 199) definiu a Responsabilidade Social Empresarial (RSE) como sendo

(...) a forma de gestão que se define pela relação ética e transparente da empresa com todos os públicos como os quais ela se relaciona e pelo estabelecimento de metas empresariais compatíveis com o desenvolvimento sustentável da sociedade, preservando

1 Disponíveis em: https://globoplay.globo.com/jornal-hoje/t/KLqhpkkZ5d/ e https:// g1.globo.com/jornal-hoje/ 
recursos ambientais e culturais para gerações futuras, respeitando a diversidade e a redução das desigualdades sociais.

Em entrevista para Lopes ([2008] 2015), o precursor da RSE, Robert Dunn, assevera que essa passou a fazer parte do cotidiano dos negócios das empresas desde 1998, vinculando-se à missão estratégica e a tudo que as organizações realizam. Ainda assevera que "Uma das conseqüências (sic) (...) da popularização da sustentabilidade empresarial é que as corporações (sic) em todo o mundo agora (sic) entendem as implicações de uma postura responsável para o sucesso do negócio" (p. A14).

Além da RSE, cabe entender alguns termos como é o caso dos já citados: SE e DS. José Pedro Martins estabeleceu conceitos para cada um desses. Assim, uma organização preocupada com a SE é uma corporação “(...) que pratica a responsabilidade social e ambiental, mantendo uma postura ética e responsável com todos os seus públicos e, como isso, provando ser uma empresa que procura contribuir para o desenvolvimento sustentável" (MARTINS, 2008, p. 20). Para efeitos da proposta deste estudo, essa será igualmente entendida como

(...) prover o melhor para as pessoas e para o ambiente no presente e com vista ao futuro. Assim, a sustentabilidade está ligada a uma visão de longo prazo e se constitui em fator de motivação para a organização que consegue conduzir suas ações de forma ética.

A empresa precisa contribuir com o desenvolvimento da sociedade, monitorando os impactos econômicos, sociais e ambientais de suas ações em relação às diversas partes interessadas. A preocupação com seus stakeholders é primordial para as operações sustentáveis de uma organização (NAVES, 2009, p. 202).

Enquanto o DS seria compreendido como sendo, segundo igualmente Martins (2008, p. 20-21), aquele desenvolvimento que, ao mesmo tempo, gera crescimento econômico; preocupa-se com o impacto desse crescimento no ambiente, refletindo sobre a natureza que se deixará para as gerações futuras; e, por fim, volta-se para o desenvolvimento e inclusão social. Dessa forma, observa-se o resultado da SE na concretização do DS. Assim, deter-se-á a atenção, neste artigo, na SE. Dantas (2009, p. 86-87) defende que 
A estratégia de sustentabilidade empresarial de uma organização deve estar integrada, de forma coerente e transversal, (sic) dentro do grupo a que a organização pertence, (sic) e basear-se no desenvolvimento de um vasto conjunto de práticas e processos, apoiados em três vertentes, que consideramos como de grande importância para as organizações - a econômica, a ambiental e a social - uma vez que, sob nosso ponto de vista, são intrínsecas à estratégia de sustentabilidade empresarial.

Félix (2009, p. 12) confirma esse posicionamento de Dantas ao defender que o tripé da sustentabilidade consegue orientar as tomadas de decisão organizacional. Conhecido como triple bottom line, o qual é constituído pelos três pilares do futuro da economia sustentável, formam os três Ps da SE e foi concebido por John Elkington na década de 1990. Salienta-se o que vem a ser cada um desses Ps, a saber: people (social), refere-se ao tratamento do capital humano de uma empresa ou sociedade, compreende: salários justos, adequação a legislação trabalhista, clima organizacional agradável, capacitação desse capital, bem como atentar para os efeitos da atividade econômica da corporação nas comunidades vizinhas local de atuação desta; planet (ambiente natural), foca-se no capital natural de uma empresa ou sociedade, o centro desse está na área ambiental, dessa maneira, o papel empresarial seria pensar nas formas de amenizar e compensar os seus impactos nesse espaço, considerando-se, principalmente, a legislação ambiental; e, por fim, profit (econômico), foca no resultado econômico de uma empresa, considerando-se os outros dois pilares.

A adoção de práticas de RSE, as quais quase sempre não conduzem que a empresa obtenha ganhos econômicos, mas que faz a organização aumentar o seu capital reputacional. Este conduzirá àqueles, o que não desagradará os investidores/acionistas, bem como angariar outros públicos simpatizantes da causa ambiental e/ou social.

Cabe ainda entender o que vem a ser o capital reputacional, a reputação e a imagem corporativas. Segundo Machado Filho e Zylbersztajn (2004), aquele pode ser compreendido como sendo aquela porção do valor de mercado da empresa que pode ser atribuída à percepção que se tem da organização como uma corporação de boa conduta no mercado. Destaca-se que é formado por várias dimensões que moldam a imagem de uma determinada corporação. Enquanto a imagem corporativa 
ção e é oriunda das informações recebidas acerca dessa empresa. (...) A formação desse conjunto de dados dependerá fundamentalmente: das informações que têm sobre a organização; da maneira pela qual adquiriram essas informações; da forma individual que se tem de agrupar essas informações em categorias; da percepção da ligação entre essas informações e outras, já existentes na memória de cada um desses indivíduos; da percepção da ligação dessas informações entre si; e, por fim, do modo pessoal de acessar as informações, de recuperar os dados que constituem os modelos, para, dessa forma, pensar sobre eles (ANDRADE, 2010).

Sobre a reputação, pode-se afirmar que é o conjunto das várias imagens na linha do tempo. Dessa forma, pode-se afirmar que "A empresa é reconhecida pelo seu nome e pelas suas apresentações, formando imagens mentais que levam à formação da reputação corporativa (...)" (MACHADO FILHO, 2002, p. 66), a qual se constitui ao longo do tempo, como já mencionado.

Assim, para se formar a imagem e, consequentemente, a reputação e o capital reputacional de uma empresa, os stakeholders vão acumulando informações acerca da organização de várias fontes, como afirmou Andrade (2010). Mas há momentos em que esses públicos se reúnem e terminam por formar o que se denomina de Opinião Pública (OP). Oskamp e Schultz ([1977] 2005) defendem que o observado é que para se formar essa opinião acerca dos mais diferentes temas/assuntos existentes na atualidade, ter-se-á que possuir acesso às informações disponibilizadas por instituições especializadas em obter e disseminar aquelas, bem como se sabe também que essas são disponibilizadas pelas próprias empresas.

Ainda se deve refletir como é formada a OP frente às questões de SE, percebe-se que se recorre as mencionadas, por Lippmann ([1922] 2008), instituições, as quais ficam a cargo dos meios de comunicação e as comunicações dirigidas da própria organização, nas quais se observa justamente a construção e divulgação do discurso da SE.

Convém compreender o que vem a ser esse discurso construído pelas/ nas/das empresas e a importância da sua elaboração consciente por aquelas. Segundo Tereza Halliday (2009, p. 32), esse discurso seria “(...) o conjunto de práticas linguísticas, semânticas e retóricas das pessoas jurídicas". Ainda assevera que "(...) os textos produzidos pelas organizações - difundidos seja por meio de fala, seja por escrito - são a manifestação primordial de seu discurso", uma vez que é a partir desses que os públicos formam a imagem 
e, consequentemente, reputação da organização com a qual termina estabelecendo relacionamentos duradouros ou não.

Dessa maneira, para difundir uma imagem favorável acerca das empresas e o discurso dessas acerca da SE, as organizações elaboram um documento, o Relatório de Sustentabilidade (RS), cujo modelo de elaboração é o da Global Reporting Initiative (GRI), adotado por milhares de organizações espalhadas pelo planeta, e é

Resultado de um conjunto de dados e de indicadores dos investimentos, além das iniciativas de cunho social direcionadas aos diversos públicos com os quais a empresa interage, esses relatórios cumprem a função de conferir transparência e dar visibilidade desses feitos, levando informações não apenas aos acionistas das companhias (shareholders, no jargão do mercado), mas também a um número maior de públicos estratégicos (stakeholders) [...] (DUARTE, 2008, p. 85).

Precisa-se entender ainda o que são as crises que algumas organizações se deparam, tem que atravessar e como devem geri-las.

Para Bland (1998), a crise seria um incidente grave que afeta a segurança humana, o ambiente e a reputação do produto/marca/empresa, que por tal receberá notoriedade negativa em termos midiáticos. Também assevera que, embora todas as crises sejam diferentes entre si, alguns elementos são sempre constantes, a saber: alguém é culpado; algo está em jogo (lucro, reputação ou sobrevivência); alguém descobre e publica.

Enquanto, para João José Forni (2013, p. 8), a crise deve ser entendida como sendo "[...] uma ruptura na normalidade da organização; uma ameaça real ao negócio, à reputação e ao futuro de uma corporação [...]". "De uma perspectiva organizacional e comunicacional, a crise coloca a posição simbólicas e o valor da organização sob séria ameaça. Por isso, requer uma intervenção rápida" (idem). Ainda de acordo com esse estudioso,

Em geral, as crises não chegam de surpresa; frustram as expectativas dos stakeholders e têm um efeito deletério perverso, por exigir energia para gerenciá-las, que poderia ser empregada para obter resultados e não apagar incêndios. Além disso, criam um clima de insegurança despertando o apetite da mídia e a pressão dos concorrentes [...]. Em essência, crises não são acontecimentos simples e fáceis de lida (p. 8-9).

A gestão de crises (GC) não deve e não é uma atividade que se realize, 
exclusivamente, quando a crise já esteja instaurada (PEREIRA; MENDES, 2006), por isso, é considerada como sendo um processo integrado que pode ser desenvolvido em três momentos, a saber: o proativo, o reativo e 0 reflexivo. Na visão de Pereira e Mendes (2006, p. 31),

\begin{abstract}
A parte reactiva (sic) (resposta à crise) está ancorada na parte mais profunda da disciplina, onde o sucesso ou insucesso da resposta à crise de facto se estabelece (parte proactiva (sic)), e se interliga necessariamente com a aprendizagem e criação de memória institucional efectuada (sic) pós a ultrapassagem de situações de crise (modo reflexivo).
\end{abstract}

Ao se ter isso em conta, cabe entender que os líderes, em situações de crise,

(...) têm de conseguir perceber que as crises são uma oportunidade e não um cataclismo que vai destruir a organização e aproveitar as sinergias que elas geram para afectuarem (sic) as mudanças necessárias de modo a que a organização na restauração do negócio possa sair mais reforçada, aproveitando a oportunidade que a crise lhe proporcionou" (PEREIRA; MENDES, 2006, p. 32).

Para Pereira e Mendes (2006), esses líderes têm que apresentar posturas para cada uma das etapas de uma crise, a saber:

- na fase proativa ou antes da crise, a liderança deve ter um comportamento antecipatório para conseguir desenvolver um conjunto de atividades que lhe permita detectar a possível crise e preparar-se para o que pode acontecer durante essa, desenvolvendo cenários e simulações;

- enquanto, na reativa ou durante a crise, deve desenvolver uma atividade essencialmente ativa a qual lhe possibilite responder, em cada momento, às novas situações que vão surgindo com transparência e consistência, demonstrando sempre as suas convicções para projetar uma imagem de integridade, bem como deve desenvolver igualmente a capacidade de tomar decisões sábias, rápidas, seguras e corajosas;

- já na reflexiva ou pós-crise, terá que aprender com a própria crise sofrida e efetuar as mudanças necessárias e adequadas a uma nova lógica de funcionamento da organização.

Feitas essas considerações de cunho teórico, passa-se a analisar como a Sustentabilidade e o discurso dessa na/da Vale foi desfeita ao sofrer a crise enfrentada a partir do rompimento da sua barragem do Córrego do Feijão 
no município de Brumadinho em Minas Gerais.

\section{ANÁlisE DA POSIÇÃO DA VALE FRENTE AO ROMPIMENTO DA BARRAGEM EM BRUMADINHO}

A Vale afirma, em seu site, durante o período estipulado para esta pesquisa, que é “(...) uma das maiores mineradoras do mundo, trabalhando com paixão para transformar recurso naturais em riqueza" (VALE, 2019a), bem como é "(...) uma empresa privada, de capital aberto, com sede no Brasil e presente em cerca de 30 países ao redor do mundo" (2019a), a qual estabelece parcerias com “(...) organizações internacionais e regionais, participando de discussões sobre políticas ambientais, comerciais, entre outras" (2019a).

Essa corporação tem como missão "Transformar recursos naturais em prosperidade e desenvolvimento sustentável” (2019b), assim como verbaliza que acredita "(...) em um (sic) mundo mais sustentável e buscamos sempre o cuidado e respeito pelo nosso Planeta” (2019b).

Integra igualmente o time de cerca de 60 dos maiores grupos empresariais do Brasil que compõe o Conselho Empresarial Brasileiro para o Desenvolvimento Sustentável (CEBDS, 2019), o qual é uma associação civil sem fins lucrativos que visa promover o DS por meio da articulação junto aos governos e a sociedade civil, além de divulgar os conceitos e práticas mais atuais acerca do DS e da SE. Esse time detém junto um faturamento equivalente a cerca de $45 \%$ do produto interno bruto (PIB) brasileiro e é responsável por mais de 1 milhão de empregos diretos no país.

Quanto à publicitação das suas ações e postura no tocante à SE, em 2017, a Vale chegou a sua $11^{\text {a }}$ edição do Relatório de Sustentabilidade. Nesse documento, a companhia

[...] apresenta as principais ações e resultados da Vale no período, inclusive informações financeiras e não financeiras relacionadas aos desempenhos econômico, ambiental e social da empresa. Esta $11^{a}$ edição do relatório foi preparada de acordo com o Global Reporting Initiative (GRI) Standards: opção abrangente e do seu Suplemento Setorial de Mineração e Metais. O conteúdo também contempla as orientações e compromissos relacionados ao Pacto Global das Nações Unidas (Global Compact), ao International Council of Mining and Metals (ICMM) e aos Objetivos do Desenvolvimento Sustentável (ODS), em conjunto com a Agenda 2030, documento das Nações Unidas que apresenta medidas concre- 
tas para promover o desenvolvimento sustentável, com o ano de 2030 como horizonte (VALE, 2017, p. 9).

Percebe-se, dessa forma, que, pelo menos em discurso, a Vale possui um compromisso com a Responsabilidade Socioambiental (RSA) - essa responsabilidade junta dois dos pilares da SE -, a SE e, consequentemente, com a DS, seguindo as diretrizes da GRI para a elaboração do referido documento e o compromisso com o preconizado nos principais documentos sobre a RSA.

Entretanto, mesmo com toda essa preocupação, em 25/01/19, por volta das 13h25, o Jornal Hoje, noticiou que "Barragem da Vale rompe em Brumadinho (MG)". Desde então, a mídia brasileira e a mundial, principalmente nas duas semanas subsequentes a esse acontecimento, foram implacáveis na cobertura da amplitude da tragédia e dos resgates das vítimas, informando a sociedade de todos os fatos transcorridos.

O resultado amplamente noticiado desse rompimento, um mês depois, foi: um saldo de mais de 300 mortos (quase metade desses ainda desaparecidos no período estipulado para este estudo); inúmeros animais (de várias espécies) igualmente falecidos; rio Paraopeba (um dos afluentes do rio São Francisco) quase morto e com danos ambientais irreparáveis; famílias sem tetos e sem ter como se manter, bem como alguns aspectos ainda careciam de maiores estudos sobre perdas ambientais e sociais. Essas perdas devem ser geridas pela Vale junto com um prejuízo de bilhões (só 71 na bolsa de valores nos primeiros dias após o desastre), contudo, seu maior dano está centrado no capital reputacional. Então, cabe entender como essa crise causou tal dano.

Como dito, muito foi divulgado sobre essa crise sem precedentes para a Vale, uma vez que envolveu muitas perdas humanas, inclusive de colaboradores que estavam no refeitório da empresa, o qual estava localizado no caminho em que o rompimento da barragem em questão atingiria. Então, onde ficou a etapa proativa de crise? Não foi prevista pela companhia em sua GC? Pelo porte e segmento da corporação, tudo indica que isso deveria estar previsto. A não retirada do grande local de encontro e alimentação dos funcionários deu-se pelo motivo de que os líderes acreditarem que estavam tentando deter o risco de rompedora da barragem com ações de engenharia, foi o que o JH noticiara no início de fevereiro. Infere-se que igualmente a Vale acreditava que um evento assim não se concretaria e que o risco seria 
contido. Contudo, num possível cenário de crise, o qual deveria estar descrito e pensado na GC da empresa, já quea represa poderia realmente romper e matar muitos que estaria em seu caminho no refeitório. Pelo noticiado no $\mathrm{JH}$, parecia que a GC foi empreendida de forma equivocada ou incompleta.

Concretizou-se o rompimento e com esse uma crise financeira, de imagem, ambiental e social. Como toda crise, a mídia foi a principal narradora da história e a reação da Vale não foi a ativa e transparente o suficiente para responder, em cada momento, às novas situações que iam surgindo, igualmente não havia consistência nas respostas dadas (a qual parecia que as lideranças da corporação não as tinham para passar aos seus stakeholders, nem convicção do que responder). Isso, com o passar dos dias, foi projetando uma imagem negativa, uma vez que os dirigentes empresariais não tinham capacidade de tomar decisões sábias, rápidas, seguras e corajosas frente as inúmeras perdas de vidas humanas e do desastre ambiental irreparável que se presenciava e que o JH dava cobertura completa.

Diante disso, o que se observou com a cobertura da mídia (neste trabaIho, a do JH) é que as narrativa eram contra o "poderio" da Vale, mesmo que o discurso atual dessa (VALE, 2019a, 2019b, 2017) (CEBDS, 2019) ainda continuava em seu site todo pautado na RSA, SE e DS. O JH abertamente "decretava" a culpa ou omissão da corporação em tomar resoluções que pudessem mitigar o risco ou o resultado de um possível rompimento da Barragem do Córrego do Feijão, tragédia concretizada em 25/01/19, como já mencionado. $\mathrm{O}$ exposto, neste Jornal, levava a OP a concluir que faltou a fase proativa e reativa na GC da companhia e que essa apenas, na figura do seu Presidente, assistia os acontecimentos, seguindo um protocolo que não dava conta do que se presenciava em Brumadinho: foram deslocados funcionários (assistentes sociais, psicólogos etc.) para o local, mas as famílias continuavam sem a precisão das informações; foram instalados filtros para conter o minério que corria e matava o rio Paraopeba, na tentativa de que esse não chegasse a outro rios e riachos, entretanto, essa ação mostrou-se apenas paliativa; diante da quase inércia da Vale, o Governo foi aplicando duras multas para que houvesse indenizações ambientais; os acionistas e os investidores perderam seu dinheiro investido ou decidiram retirá-lo diante do cenário delineado; entre outros grave fatos contra a Vale.

$O$ dano à sua imagem e, consequentemente, ao seu capital reputacional, foi um prejuízo percebido e o qual perdurará por muito mais tempo do que os demais, a exemplo do material, uma vez que esse tem recuperação 
mais rápida no caso de uma corporação como é o caso da Vale. Na visão de Marcelo Marchesini (apud PACHECO, 2019), o qual é o coordenador do Programa Avançado em Gestão Pública do Insper,

Isso [dano imagético] vai exigir da mineradora uma série de ações mais estruturantes de compromisso não só com as vítimas desse incidente, mas a demonstração para as comunidades onde atua, para governos e sociedade de uma forma geral que as suas preocupações com seus impactos vão se sobrepor a essa preocupação com o lucro.

Inferia-se, antes da crise em questão, que a Vale era uma corporação que adotava práticas para o gerenciamento de crise, o que deveria capacitar os seus dirigentes a saber lidar com pressões de toda ordem e advindas de todos os seus stakeholders. Dessa forma, as lideranças tinham que estar preparadas e ter em mente que os seus públicos estratégicos iriam continuar a exigir resultados a todo custo e em todas as crises; outros públicos pressionariam por um maior e real comprometimento ambiental e social da Vale nesta e em outras possíveis crises; e até os próprios funcionários poderiam exigir mais respeito por suas vidas durante o período em que estão trabalhando. A nação, como um todo, deve esperar e cobrar uma reação do Governo à crise em Brumadinho, bem como pela postura e pelo comportamento governamental sobre as regras para fiscalização para esse tipo de situação e a punição da Vale. O que se esperava é que essa companhia deveria se ajustar e adiantar-se em algumas ações de reconhecimento do seu erro, mesmo com o risco de ser ainda multada, ter mais recursos apreendidos e pagar indenizações gigantescas. Entretanto, a pressão da OP e a perda de imagem já se constituíam, na época delineada para a feitura deste trabalho, uma realidade a ser gerida pela corporação e que

O impacto para a sociedade é relevante demais para o governo lavar as mãos. A política ambiental tem um peso importante entre acionistas, por isso vai ser tão importante que decisão será tomada sobre o aspecto regulatório, do contrário, veremos a pressão por resultados no mercado de mineração ter um impacto sobre as questões ambientais (MARCHESINI apud PACHECO, 2019).

O que se percebeu foi que, mesmo a Vale, cujo líderes deveriam ser capacitados a posicionar-se para sanar ou melhorar o conflito vivenciado, pode colocar-se de forma equivocada a partir de uma fala de um gestor, o que 
termina por gerar mais imagem negativa na que já se encontrava fragilizada. Esse foi o caso ocorrido com Fabio Schvartsman, presidente da organização, que afirmou, na Câmara dos Deputados, na audiência pública na Comissão Externa, ocorrida em 21/02/19 e noticiada pelo JH, que a Vale seria "uma joia" e, por isso, não poderia ser "condenada" pelo rompimento da barragem "por maior que tenha sido a tragédia". Essa declaração, especificamente, gerou irritação entre os parlamentares e a OP em geral, indicando que o cuidado com a escolha das palavras pode ser um índice de que a crise está sob controle, o que não foi demonstrado neste episódio. Isso também mostra o despreparo frente ao enfrentamento consciente da crise vivenciada pela corporação. Ao escolher a palavra "tragédia" retirava a culpa da corporação no ocorrido, o que piorou a imagem da empresa frente aos stakeholders.

A fase reflexiva não pode ser analisada neste trabalho, pois o recorte temporal estabelecido foi demasiadamente curto para se chegar a essa. Mesmo a fase reativa não foi completamente examinada, uma vez que a crise só tinha sido deflagada e só algumas ações foram empreendidas e focadas neste estudo.

Figura 1: Tripé da sustentabilidade e conceito de Desenvolvimento Sustentável

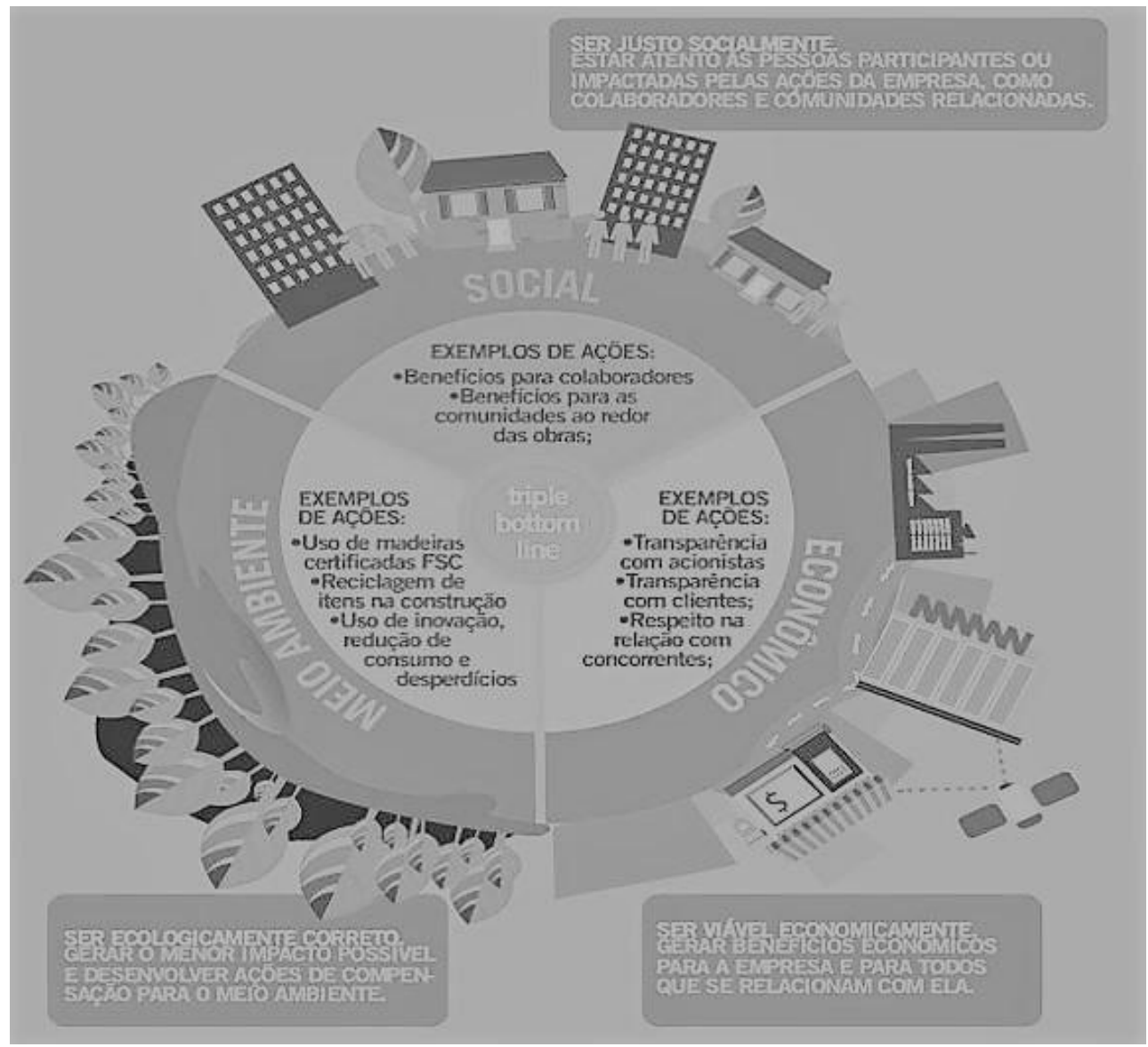

Fonte: Prado (2018). 
Por fim, ao se examinar o tripé da SE (Figura 1), observa-se que a Vale não foi, nesta crise:

- justa socialmente, já que não estava atenta as pessoas impactadas pelas suas ações, como foi o caso dos seus funcionários e das comunidades circunvizinhas;

- ecologicamente correta, pois não se preocupou o necessário com o impacto ambiental de suas ações e como poderia desenvolver uma compensação à sua atividade predatória;

- viável economicamente, uma vez que gerou enormes perdas financeiras para a própria companhia e para todos os seus stakeholders, principalmente, os acionistas e investidores.

\section{CONSIDERAÇÕES FINAIS}

Ao final deste estudo, percebe-se que lidar com o desastre, com perdas volumosas de valores monetários, com o seu discurso acerca da SE sendo desmontado, com a pressão do Governo e da mídia como um todo, bem como com uma OP que lhe é adversa é um cenário que mesmo uma "gigante' como a Vale tem dificuldade de enfrentar.

Observa-se igualmente que as crises de imagem e perdas substanciais de capital reputacional são aspectos que levam tempo para serem tratados e esquecidos, mesmo para empresas desse porte.

Em situações como a do rompimento de uma barragem com danos ambientais e sociais irreparáveis, até empresas, como a Vale, não conseguem sustentar a sua imagem corporativa positiva e, quando o desastre vem, junto a esse, virá, fatalmente a perda igualmente irreparável de reputação. Os prejuízos em todas as esferas a OP brasileira pode até esquecer, mas a OP mundial não tem o mesmo comportamento, uma vez que, para esta, desastres ambientais e sociais ficam na memória dessa opinião mais politizada por muito mais tempo.

O que se aprendeu, com a feitura deste trabalho, é que o discurso tem que vir acompanhado de uma prática real de consciência da necessidade do respeito e da preservação da vida humana e do meio ambiente; que mesmo corporações como a Vale não estão imunes ao "tribunal" da OP e a construção de uma imagem/de uma reputação positiva perpassam pela percepção que essa opinião possui das ações que a organização tem frente a algumas questões, não bastando apenas apresentar um discurso que vise "agradar" os seus públicos estratégicos. 
CADERNOS DE COMUNICAÇÃO

UNIVERSIDADE FEDERAL DE SANTA MARIA

\section{REFERÊNCIAS}

ANDRADE. Marta Cardoso de. Imagem empresarial. Salvador. 8 jul. 2010. Disponível em: <https://dramartaandrade.blogspot.com/search?q=imagem>. Acesso em: 27 fev. 2019.

BLAND, Michael. Communicating out of a Crisis. London: MacMillian Press Ltd., 1998.

CEBDS. Quem somos. Disponível em: <https://cebds.org/quem-somos/>. Acesso em: 3 fev. 2019 .

COMIN, Arnaldo. Entrevista com John Elkington. Revista ESPM, São Paulo, ano 22, 102. ed., n. 2, p. 12-17, mar-abr. 2016.

DANTAS, Edmundo Brandão. Imagem organizacional e imagem de marca. In: FÉLIX, Joana d'Arc Bicalho; BORDA, Gilson Zehetmeyer (Orgs.). Gestão da Comunicação e Responsabilidade Socioambiental: uma nova visão de Marketing e Comunicação para o desenvolvimento sustentável. São Paulo: Atlas, 2009. p. 51-94.

DUARTE, Soraia de Oliveira. Informação S/A: o valor da comunicação para companhias abertas e para investidores. São Paulo: Saraiva, 2008.

FÉLIX, Joana d'Arc Bicalho. Comunicação e movimento ambiental. In: FÉLIX, Joana d'Arc Bicalho; BORDA, Gilson Zehetmeyer (Orgs.). Gestão da Comunicação e Responsabilidade Socioambiental: uma nova visão de Marketing e Comunicação para o desenvolvimento sustentável. São Paulo: Atlas, 2009. p. 3-14.

FORNI, João José. Gestão de crises e comunicação: o que gestores e profissionais de Comunicação precisam saber para enfrentar crises corporativas. São Paulo: Atlas, 2013.

HALLIDAY, Tereza Lúcia. Discurso organizacional: uma abordagem retórica. In: KUNSCH, Margarida M. Krohling (Org.). Comunicação organizacional: linguagem, gestão e perspectivas. v. 2. São Paulo: Saraiva, 2009, p. 31-52.

LIPPMAN, Walter. Opinião pública. Tradução e prefácio de Jacques A. Wainberg. Petrópolis, RJ: Vozes, [1922] 2008. (Coleção Clássicos da Comunicação Social).

LOPES, Juliana. Entrevista Robert Dunn: um conceito que evolui e se populariza. Gazeta Mercantil, São Paulo, 1 abr. 2008. p. A14. Disponível em: <http://www.synergos.org/08/ gazetamercantilentrevistadunn.pdf>. Acesso em: 10 nov. 2015.

MACHADO FILHO, Cláudio Antonio Pinheiro; ZYLBERSZTAJN, Decio. Capital reputacional e responsabilidade social: considerações teóricas. Caderno de Pesquisas em Administração. São Paulo, v. 11, n. 2, p. 87-98, abril/jun. 2004.

MACHADO FILHO, Cláudio Antonio Pinheiro. Responsabilidade social corporativa e a criação de valor para as organizações: um estudo multicasos. 2002. 204 f. Tese (Doutorado) - Faculdade de Economia, Administração e Contabilidade da Universidade de São Paulo. São Paulo: FEA/USP, 2002.

MARTINS, José Pedro Soares. Responsabilidade Social Corporativa: como a postura responsável compartilhada pode gerar valor. Campinas, SP: Komedi, 2008. (Coleção Sustentabilidade Corporativa).

MASI, Domenico de. A sociedade pós-industrial. São Paulo: SENAC, 1999.

NAVES, Rubens. Responsabilidade social, sustentabilidade e governança corporativa em 
um contexto ético. In: KUNSCH, Margarida Maria Krohling; OLIVEIRA, Ivone de Lourdes (Orgs.). A comunicação na gestão da sustentabilidade das organizações. São Caetano do Sul, SP: Difusão, 2009. (Série Pensamento e Prática, 2). p. 197-209.

OSKAMP, Stuart; SCHULTZ, P. Wesley. Attitudes and opinions. 3rd ed. Mahwah, NJ, USA: Lawrence Erlbaum Associates Publishers, [1977] 2005.

PACHECO, Paula. Vale perde R\$ 71 bilhões em valor de mercado após tragédia em Brumadinho. em.com.br, 29 jan. 2019. Disponível em: <https://www.em.com.br/app/noticia/ economia/2019/01/29/internas_economia,1025546/vale-perde-r-71-bilhoes-em-valor-de-mercado-apos-brumadinho.shtm>. Acesso em: 26 fev. 2019.

PEREIRA, Francisco Costa; MENDES, António Marques. Uma visão estratégica sobre a gestão de crises. In: (Coords.). Crises: de ameaças a oportunidades - gestão estratégica de comunicação de crises. Lisboa: Edições Sílabo, LDA., 2006.

PRADO, Paulo Braga. 0 tripé da sustentabilidade. (2008). Disponível em: <http://mundoparamorar.com.br/2011/07/08/os-infograficos-da-even/>. Acesso em: 23 nov. 2018.

VALE. Sobre a Vale. Disponível em: <http://www.vale.com/brasil/PT/aboutvale/Paginas/ default.aspx>. Acesso em: 25 fev. $2019 a$.

VALE. Missão, Visão e Valores. Disponível em: <http://www.vale.com/brasil/PT/aboutvale/ mission/Paginas/default.aspx>. Acesso em: 25 fev. 2019b.

VALE. Relatório de Sustentabilidade 2017. Disponível em: <http://www.vale.com/Style\%20 Library/RelatorioSustentabilidade17/PT/VALE_RelatorioSustentabilidade_2017.pdf >. Acesso em: 3 fev. 2019. 


\section{Marta Cardoso de Andrade}

Professora Adjunto dos Curso de Relações Públicas, Jornalismo e Comunicação e Marketing. Líder e Pesquisadora do Grupo de Pesquisa Com2D, vinculado ao CNPq. Pós-Doutora em Ciências da Comunicação pela Universidade Nova de Lisboa; Doutora e Mestra em Letras, UFBA, corpus em Comunicação Organizacional; Bacharela em Comunicação Social, UNIFACS, e Licenciada Plena em Língua Portuguesa, UNEB. E-mail: dramartaandrade@gmail.com 